Document downloaded from:

http://hdl.handle.net/10251/158853

This paper must be cited as:

Higuera-Trujillo, JL.; Llinares Millán, MDC.; Montañana I Aviñó, A.; Rojas, J. (2020). Multisensory stress reduction: a neuro-architecture study of paediatric waiting rooms. Building Research \& Information. 48(3):269-285. https://doi.org/10.1080/09613218.2019.1612228

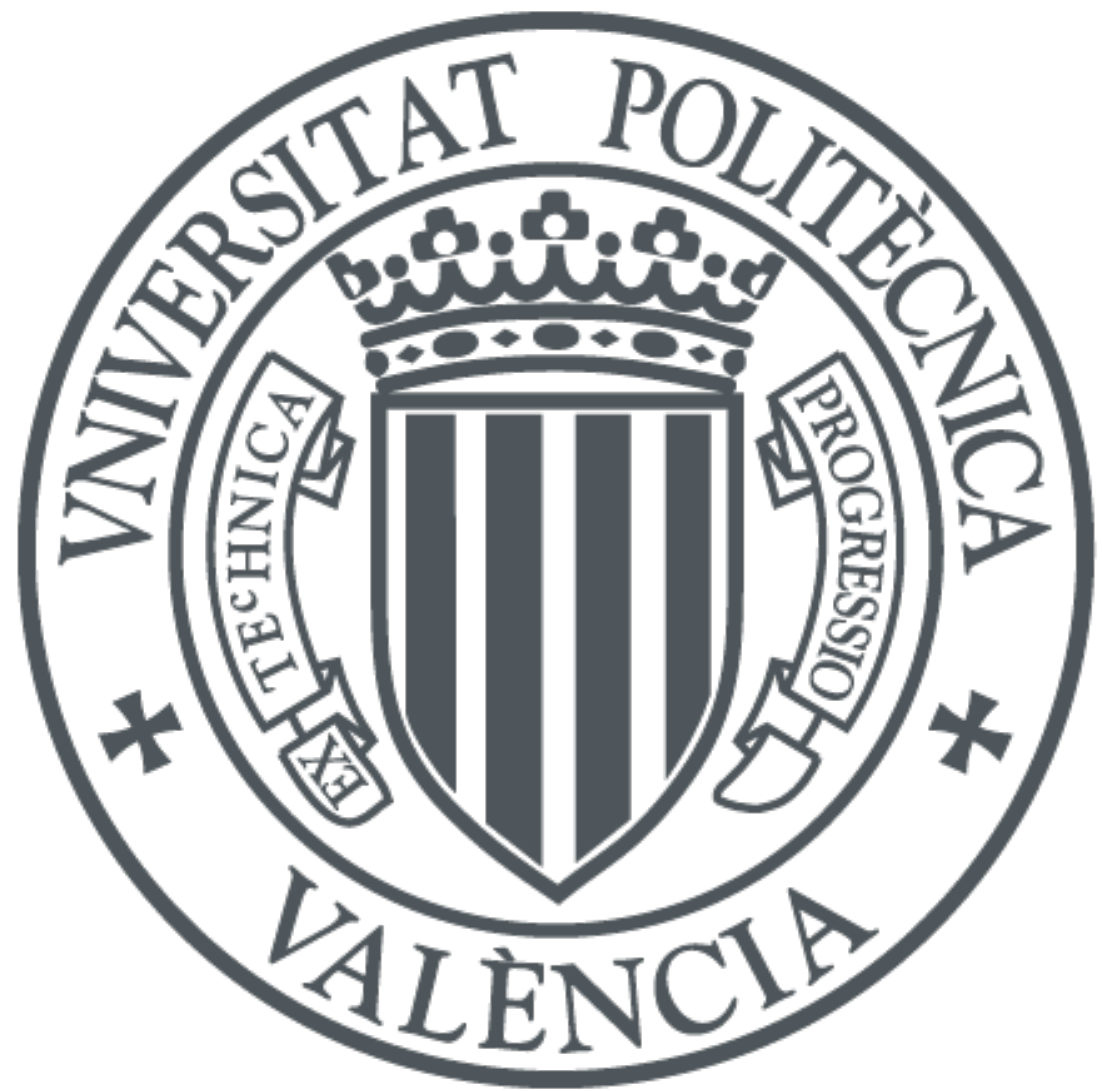

The final publication is available at

https://doi.org/10.1080/09613218.2019.1612228

Copyright Taylor \& Francis

Additional Information 


\section{Multisensory stress reduction: a neuro-architecture study of paediatric waiting rooms.}

Higuera-Trujillo, Juan Luis ${ }^{a *}$, Llinares Millán, Carmena, Montañana i Aviñó, Antoni ${ }^{\mathrm{a}}$, and Rojas, Juan-Carlos ${ }^{\mathrm{b}}$

${ }^{a}$ Institute for Research and Innovation in Bioengineering (i3B) - Universitat Politècnica de València, Valencia, Spain; ${ }^{b}$ Escuela de Arquitectura, Arte y Diseño (EAAD) Tecnologico de Monterrey, Monterrey, Mexico

Juan Luis Higuera-Trujillo. Institute for Research and Innovation in Bioengineering. Ciudad Politécnica de la Innovación - Cubo Azul - Edif. 8B - Acceso N. Camino de Vera s/n, 46022 - Valencia (SPAIN). Email: jlhiguera@i3b.upv.es. Telephone: +34 963877518.

Higuera-Trujillo, Juan Luis. ORCID: 0000-0003-1870-2388. jlhiguera@i3b.upv.es Llinares Millán, Carmen. ORCID: 0000-0003-2270-807X. cllinare@omp.upv.es Montañana i Aviñó, Antoni. ORCID: 0000-0003-2749-6248. amonav@upvnet.upv.es Rojas, Juan-Carlos. ORCID: 0000-0001-7718-4555. jcrojasl@itesm.mx

\section{Funding}

This work was supported by the Ministerio de Economía y Competitividad of Spain under Grant TIN2013-45736-R.

\section{Disclosure statement}

No potential conflict of interest was reported by the authors. 


\section{Multisensory stress reduction: a neuro-architecture study of paediatric waiting rooms.}

The implementation of environmental satisfaction sources in the design of a health centre is a means to achieve stress reduction. The present work analyses the effect that these sources have on the stress reduction of patients' companions in a paediatric service. A two-phase study was carried out. During the first phase, 120 participants assessed 20 waiting rooms in situ in order to select the environmental sources with the greatest effect. During the second phase, the stress levels of 26 participants were measured in four simulated waiting rooms that combined the selected sources from the first phase. A multisensory simulation was carried out through a virtual reality experiment with visual, auditory and olfactory elements, and stress levels were measured at the psychological and neurophysiological levels. Results suggest that a combination of environmental satisfaction sources creates an important synergistic effect at the psychological and neurophysiological levels and underlines the importance of auditory and olfactory stimuli. Conclusions may be of interest to designers and managers of healthcare facilities.

Keywords: waiting room design; healthcare; stress reduction; multisensory stimulation; neuro-architecture 


\section{Introduction}

Stress is an interrelation between a subject and the environment that occurs when the subject evaluates his or her resources as insufficient to meet the demands of the environment (Lazarus \& Folkman, 1984). In healthcare, this state can cause a wide variety of negative effects that worsen patients' recovery and satisfaction (Ulrich, Quan, Zimring, Joseph, \& Choudhary, 2004). Paediatric services represent a special challenge because of unforeseen behaviours and levels of stress that children may display (Gorski, Slifer, Kelly-Suttka, \& Lowery, 2010). Despite the importance of stress in this context, $50 \%$ of patients still consider health centres stressful (Gates, 2008), suggesting that more needs to be done in the design and management of paediatric waiting rooms.

This stress not only affects patients but also extends to staff and patients' companions. Scholars have found that stress influences staff health (Devereux, Rydstedt, Kelly, Westo, \& Buckle, 2004) and execution of errors (Scott, Hwang, \& Rogers, 2006). A child's stay in hospital can also be highly stressful for companions. Among children's companions, stress is associated with a series of physical and psychological outcomes that include anxiety, depression, fatigue and interruption of sleep (Busse, Stromgren, Thorngate, \& Thomas, 2013), which has further negative effects on the child (Whelan \& Kirkby, 2000). Companions' stress has scarcely been studied, and, in the case of parents, mitigation measures are mainly based on their psychological preparation to face the situation.

Stress in healthcare facilities is caused not only by the illness and the related medical procedures but also by the context. Many studies have shown that it is possible to address the psychological state of patients and companions by means of space design (Leather, Beale, Santos, Watts, \& Lee, 2003), which may even have a healing effect (Zhang, Tzortzopoulos, \& Kagioglou, 2019). However, these studies generally have 
limitations: (1) they focus on analysing one isolated variable, whereas real spaces have a combination of variables (Andrade \& Devlin, 2015); (2) the quantification of stress is carried out through self-reports, which are subject to biases (Schwarz \& Strack, 1999) such as the participants' difficulty in expressing psychological status; and (3) where environmental simulations are used as stimuli, they are usually photos or plans, which evoke different psychological responses from those evoked by the physical spaces that they represent (Higuera-Trujillo, López-Tarruella, \& Llinares Millán, 2017).

The objective of this study is to analyse the effect that certain characteristics of the design of paediatric waiting rooms have on companions' stress reduction, addressing the aforementioned limitations. Using neurophysiological and psychological measures, we analyse the effect of combinations of different environmental satisfaction sources on stress levels. Virtual reality was used for the environmental simulation. The choice of context was based on the fact that waiting rooms are spaces used by the general public and, in particular, that paediatric waiting rooms cause high levels of stress in children and their companions.

\section{The effect of healthcare facility design on stress}

Various theoretical frameworks of healthcare environmental design and emotional support have been developed. In these frameworks, emotional support is interpreted as the actions carried out to support psychological needs and promote health and healing through the design of spaces in healthcare facilities (Schweitzer, Gilpin, \& Frampton, 2004). One of the principal frameworks is Ulrich's theory of supportive design (1991). According to this framework, healthcare facilities have to foster three components: sense of control, social support and positive distractions. Many applied studies have been based on this framework. For example, it has been shown that different aspects of hospital rooms contribute to stress reduction (Andrade, Devlin, Pereira, \& Lima, 2017) 
and that the sense of control affects companions in similar contexts to paediatric waiting rooms (Suter \& Baylin, 2007). In addition to this framework, others have focused on taking account of patients' needs in the design process, citing 'interior design features', 'architectural features', 'maintenance features', 'social features' and 'ambient environment features' (Harris, McBride, Ross, \& Curtis, 2002). In general, this discussion shows that interest in this dimension of health spaces has risen in recent times.

In most studies, the quantification of stress levels is carried out by means of selfreport. This analysis, whether carried out through quantitative, qualitative or combined means (Higuera-Trujillo, Montañana i Aviñó, \& Llinares Millán, 2017), is limited when registering participants' unconscious processes or when studying them in real time (Reinerman-Jones, Sollins, Gallagher, \& Janz, 2013). Thus, the state reported by the user may differ from the reality, and state variations are difficult to study because the report covers a broad time segment. In this regard, the technologies applied in neuroscience can contribute by offering a higher level of objectivity. These technologies cover several manifestations of the nervous system. Among them are electrodermal activity (EDA), which measures variations in skin perspiration, electrocardiograms, which measure heart rate variability (HRV), and electroencephalograms (EEGs), which measure variations in the electrical activity on the surface of the scalp. A considerable amount of literature has presented analyses to obtain stress metrics (Campbell \& Ehlert, 2012). These analyses can enhance knowledge about stress reduction through design.

\section{Design variables}

The environmental satisfaction sources studied in the literature focus on healthcare facilities and different sensory modalities. Accordingly, it is possible to find analyses focused on visual, auditory and olfactory variables. 
In the visual modality, nature and design variables have been most frequently studied. In general, they can improve the user experience. They have been widely studied as sources of satisfaction, and they have even been proposed as therapy (Avrahami, 2006).

- Regarding nature, Ulrich (1991) proposed design patterns based on wild nature for healthcare facilities. Related studies have shown that this positive effect extends even to realistic nature photographs, reducing patients' stress (Nanda, Eisen, Zadeh, \& Owen, 2011) and improving evaluations of waiting rooms (Beukeboom, Langeveld, \& Tanja-Dijkstra, 2012).

- Regarding design, it has been shown that lighting, colour and architectural design variables generate the perception that better medical attention is being offered (Baker \& Cameron, 1996). In this regard, it has been suggested that neuro-aesthetics can provide a source of pleasure in the healthcare environment (Nanda, Pati, \& McCurry, 2009). The placement of furniture, even without modifying the architectural configuration, also has this capacity (Arneill \& Devlin, 2002).

In the auditory modality, music and sounds of nature variables have frequently been studied both independently and in conjunction with visual ones. Including this type of stimuli can facilitate the health processes faced by the patient without negatively influencing the staff's responsibilities (Waldon \& Thom, 2015).

- Music can contribute to reducing stress levels in both controlled laboratory conditions (Thoma et al., 2013) and in healthcare (Moola, Pearson, \& Hagger, 2011). For example, it has been found that music reduces patients' pain in preoperative (Lee, Chao, Yiin, Chiang, \& Chao, 2011) and post-operative situations 
(Özer, Özlü, Arslan, \& Günes, 2013) and in emergency service waiting rooms (Holm \& Fitzmaurice, 2008). This stress-reducing effect has also been found in the case of companions (Routhieaux \& Tansik, 1997).

- Sounds of nature can reduce the stress levels of patients (Saadatmand et al., 2013). It has also been found that they reduce the pain of invasive procedures combined with related visual stimuli (Diette, Lechtzin, Haponik, Devrotes, \& Rubin, 2003).

In the olfactory modality, these stimuli have been found to have a positive effect on psychological and behavioural processes (Herz, 2009). A variety of scents have been studied, notably lavender and orange. However, although aromatherapy implementation in healthcare facilities has a long history and significant benefits (Cannard, 1996), this modality has been addressed by few studies.

- Lavender is one of the most frequently studied fragrances (Fenko \& Loock, 2014). It has been observed to have benefits in reducing stress in neonatal (Kawakami et al., 1997), needle insertion (Kim et al., 2011), postpartum (Kianpour, Mansouri, Mehrabi, \& Asghari, 2016), and palliative care contexts (Berger, Tavares, \& Berger, 2013). In the staff sector, this scent also contributes to reducing stress (Sung \& Eun, 2007) and improving performance (Birnbach, King, Vlaev, Rosen, \& Harvey, 2013).

- The scent of orange, although it has been less widely studied, has been shown to reduce stress in healthcare facilities. Contexts where this effect has been observed include women waiting in the dentist's office (Lehrner, Eckersberger, Walla, Pötsch, \& Deecke, 2000) and pregnant women in childbirth units (Rashidi-Fakari, Tabatabaeichehr, \& Mortazavi, 2015). 
More often than not, these studies use photographs or videos to simulate the environmental satisfaction sources. Although this approach may be valid, it has certain weaknesses. Among other weaknesses, photographs and videos lack interactivity, are subject to external distractors, and do not reproduce olfactory stimuli. Consequently, experience differs substantially from reality (de Kort, Ijsselsteijn, Kooijman, \& Schuurmans, 2003). In this sense, virtual reality can contribute by generating multisensory experiences that are more similar to reality because it can provide visual, auditory and olfactory simulation. Thus, it offers the chance to develop experiences which generate a sense of presence or 'being there' (Steuer, 1992), in an immersive interactive simulation. Moreover, viewed in head-mounted displays (HMDs), visual information of the physical environment is completely replicated. Consequently, using these technologies can help us reach new conclusions about the psychological effect of space design.

\section{Method}

The method was structured in two phases. Both phases were oriented toward studying the effect that different environmental satisfaction sources in paediatric waiting rooms have on companions' stress. This division allowed to limit the number of sources to be analysed: in the first phase, the sources with greater effect in reducing stress were identified in physical waiting rooms; and in the second phase, these sources were analysed in an isolated and combined way under controlled laboratory conditions. Table 1 shows the most relevant features.

The general characteristics of the two phases are as follows:

In Phase I, we identified the environmental satisfaction sources in paediatric waiting rooms that have the greatest effect on companions' stress reduction. This was done by reviewing the relevant literature, which resulted in 19 sources. The field study 
was carried out in situ, given that context could affect the responses. In this phase, 120 children's companions assessed the effect of 19 environmental satisfaction sources (see Figure 4) on stress in 20 paediatric waiting rooms located in Spain. These waiting rooms were located in the Valencian Community, a Mediterranean region located in the southeast of Spain with approximately 5 million inhabitants. In this region, we selected representative waiting rooms of municipalities with more than 50,000 inhabitants, using the technique of reduction of the affinity diagram. The number of 20 waiting rooms offered a sample that the research team considered sufficiently representative and differentiated of waiting room designs. A stress self-assessment was also used to ensure that the participants were in a highly stressful situation when they assessed sources. Our results show the environmental satisfaction sources with the greatest effect on stress reduction for the context studied.

In Phase II, we identified the combination of environmental satisfaction sources (CESS) identified during Phase I that had the greatest effect on stress reduction. The field study was carried out in a laboratory, using immersive virtual reality systems. In this study, 26 children's companions were exposed to four different CESS in a virtual waiting room, and psychological and neurophysiological responses related to stress were observed. Simulations were validated through the participants' sense of presence, measured through psychological responses (Phase IIA). Subsequently, psychological and neurophysiological responses were obtained to analyse participants' stress levels. For psychological responses, stress self-assessments were used. For neurophysiological responses, the metrics of EDA, HRV and EEG were used. The results show the effect of CESS on stress reduction at the psychological (Phase IIB) and neurophysiological (Phase IIC) levels and the relationship between their metrics (Phase IID). [Table 1 near here] 


\section{Materials and methods}

This section describes the materials and methods used in Phase I and Phase II.

\section{Phase I}

Phase I focused on identifying the environmental satisfaction sources with the greatest effect on stress reduction. A sample of participants in a real waiting situation in physical waiting rooms completed a questionnaire on the impact of different sources of environmental satisfaction on stress. The questionnaire also assessed their state of stress.

Participants. Participants were 120 fathers or mothers of children who are users of a paediatric service. The sample was gender balanced (60 women and 60 men), and the average age was 37 years $(\sigma=6.77)$. The selection was based on the criterion that companions be within the first degree of consanguinity, the most common children's companion profile.

Stimuli. The stimuli were applied in 20 paediatric service waiting rooms in various healthcare institutions (both in hospitals and in community health centres). We tried to compile a varied set, given the 'nesting' limitation that can arise when working with real stimuli (Kish, 1995). Each room was assessed in situ by six participants (three men and three women).

Questionnaire. Two types of questions were asked of each participant:

- Assessment of the stress level in each waiting room with the question 'At this moment, I feel a stress level...' followed by a Likert scale ranging from -2 to 2 in increments of half points.

- Assessment of the contribution of 19 environmental satisfaction sources that are characteristic of waiting room spaces in general in terms of their effect on stress 
reduction. The selection of these sources was carried out by the work group (consisting of two members of the research team, two external architects, two fathers and two mothers of children who use a paediatric service), taking into consideration the bibliography and previous visits to the 20 waiting rooms considered in the study. The environmental satisfaction sources were 'space for baby buggies', 'furniture arranged facing one another', 'furniture arranged in groups', 'silence', 'sounds of nature', 'adjustable lighting in each section of the waiting room', 'furniture arranged not facing one another', 'space for companions', 'non-intense lighting', 'appropriate signage', 'adjustable temperature in each section of the waiting room', 'nature pictures', 'natural lighting', 'vending machine', 'nice scent', 'pictures for children', 'non-intense music', 'vegetation' and 'play facilities for children'. The assessment was performed using the question 'For the waiting rooms of the paediatric service in general, this source contributes to reducing stress...' followed by a scale ranging from 0 to 10 .

The participants completed the questionnaire during their waits in the stimuli rooms. They all waited for between 15 and 30 minutes to mitigate possible differences, given that this is an important factor in these experiences (Magaret, Clark, Warden, Magnusson, \& Hedges, 2002).

Data analysis. After the database had been compiled and anonymized, the statistical analysis was carried out. The average of each environmental satisfaction source was obtained to identify the sources that have the greatest effect on stress reduction. IBM SPSS software was used (v.17.0; www.ibm.com/products/spssstatistics). 


\section{Phase II}

Phase II focused on identifying how a combination of CESS has an influence. For that purpose, participants in a stressful situation (generated by means of a psychological stressor) were exposed to different CESS in a waiting room through environmental simulation set-ups, and psychological and neurophysiological metrics of the stress levels were recorded. All participants visualized a training scenario for a few minutes before starting the experiences to improve their adaptation to the virtual reality set-up. Figure 1 shows the general sequence. [Figure 1 near here]

Participants. Participants were 26 fathers or mothers of children in the paediatric service. The data for two participants were removed because of neurophysiological acquisition problems in one case and the exclusion criteria described below in the other. The final sample (24) was gender balanced (54\% male and $46 \%$ female), and the average age was 37 years $(\sigma=3.99)$.

There were three selection criteria: children should be users of the paediatric service, should not suffer from any condition with contraindications for the use of virtual reality technologies, and should have normal or corrected-to-normal vision with contact lenses.

Psychological stressor. Before experiencing the CESS, the participants were exposed to a psychological stressor. This consisted of the performance of arithmetic tasks, for 120 seconds, based on the Montreal Imaging Stress Task (Dedovic, Renwick, Mahani, \& Engert, 2005) and adapted for difficulty for each subject by means of a previous task.

With the aim of verifying stress generation, the interviewer asked the participants to self-assess their stress levels using a Likert-type scale ranging from -2 to 2. All participants reported high stress levels $(X=1.41, S=0.590)$, so the stressor was 
considered appropriate. Although the stress generated by this method may differ from the experiences that the experiment is designed to simulate, it is an appropriate approximation in laboratory conditions (Moya-Albiol \& Salvador, 2001).

CESS configurations. The base stimulus was always the same (a visual, auditory and olfactory replica of the real waiting room that was considered standard). On this base stimulus, three different CESS were implemented. The choice of environmental satisfaction sources was based on the results of Phase I ('nice scent', 'pictures for children', 'non-intense music', 'vegetation' and 'play facilities for children') in order not to make the combinations so complicated as to be impracticable. The play facility for children was fixed as a constant because it is common in Spain, and the other four were grouped according to their affinity described by Harris et al. (2002) with 'interior design features' (vegetation and pictures for children) and 'ambient environment features' (non-intense music and a nice scent). Specifically, the composition Miserere mei, Deus by Gregorio Allegri (Thoma et al., 2013) and the scent of lavender (Fenko \& Loock, 2014) were chosen because they were evaluated as relaxing. In this way, four CESS configurations were developed. Table 2 specifies each CESS configuration, according to the sensory modalities. All the participants were exposed to the four configurations, following an incomplete counterbalancing design. [Table 2 near here]

Environmental simulation set-ups. The CESS experiences were carried out by means of visual, auditory and olfactory environmental simulations. The following devices were used:

- HTC Vive. Visual stimulation. An HMD developed by HTC and Valve (www.vive.com). This displays $2160 \times 1200$ pixels $(1080 \times 1200$ per eye) with a field of view of 110 degrees and a $90 \mathrm{~Hz}$ refresh rate. Figure 2 shows both types 
of CESS configurations (CESS\#1 and \#2; CESS\#3 and \#4) at the visual stimulation level. [Figure 2 near here]

- HD 558. Auditory stimulation. Headphones developed by Sennheiser (www.enus.sennheiser.com). Two types of CESS configurations were reproduced at auditory level: CESS\#1 and \#3, a binaural recording of the ambient noise in a paediatric waiting room; and CESS\#2 and \#4, the simulation of a loudspeaker system broadcasting Miserere mei, Deus.

- Scentpalette. Olfactory stimulation. Aromatizing device developed by HeadHunter 2000 (www.scentpalette.com). Two types of CESS configurations were spread at olfactory level: CESS\#1 and \#3, a hospital smell (modification of a eucalyptus and bleach base), and CESS\#2 and \#4, a lavender scent.

Figure 3 shows one of the experiences. [Figure 3 near here]

Data processing. Psychological and neurophysiological data were recorded for each participant. iMotions (v.6.1; www.imotions.com) was used on the research PC to manage the protocol and compile the data.

Psychological data. These data were focused on measuring the participants' stress and sense of presence evoked by the experiences of the CESS. For stress metrics, a stress self-assessment and the State-Trait Anxiety Inventory were used, and, for sense of presence, a SUS questionnaire was used.

- Stress self-assessment. Assessment of stress by means of a Likert scale ranging from -2 to 2 . The question 'This waiting room has caused me stress...' was used.

- State-Trait Anxiety Inventory. Test that assesses anxiety as a trait and as a state, developed by Spielberger, Gorsuch, and Lushene (1970). It consists of two 
inventories, one for each concept (Trait Anxiety Inventory and State Anxiety Inventory). Both contain 20 items evaluated by means of a Likert scale ranging from 1 to 4, with the outcomes being transformed into percentiles. Using the Trait Anxiety Inventory, participants under and over the $25^{\text {th }}$ and $75^{\text {th }}$ percentiles were excluded (one was removed) to avoid possible anomalies (Maxfield \& Melnyk, 2000).

- SUS questionnaire. Presence test developed by Slater, Usoh, \& Steed (1994). This measures level of presence through six items on a Likert scale ranging from 1 to 7 . This assessed whether the simulations could be considered satisfactory.

Neurophysiological data. These data were used to complement the psychological data. Electrodermal, heart-rate variability, and electroencephalogram metrics related to stress were used.

- Electrodermal activity (EDA). Analysing this signal reveals its phasic component, an indicator of sympathetic activity. The EDA signal was recorded at $128 \mathrm{~Hz}$ using a Shimmer 3GSR+ device (www.shimmersensing.com). The raw signal was pre-processed and analysed using Ledalab (v.3.4.8, www.ledalab.de) via Matlab (v.2016a; www.mathworks.com). Pre-processing consisted of (1) Butterworth low-pass signal filtering at $2.5 \mathrm{~Hz}$ (Valenza \& Scilingo, 2014), (2) signal downsampling to $10 \mathrm{~Hz}$ (Lang, Zhou, Schwartz, Bolls, $\&$ Potter, 2000) and (3) visual-diagnostic of artefacts and their corrections. The CDA (Continuous Decomposition Analysis) method was used to calculate the phasic metric (Benedek \& Kaernbach, 2010). Thereafter, the values were standardized following Venables \& Christie (1980). 
- Heart-rate variability (HRV). Analysing this signal in the frequency domain makes it possible to distinguish the ratio between low frequency to high frequency $(\mathrm{LF} / \mathrm{HF})$. This ratio is a balance indicator of sympathetic activity over parasympathetic activity (Malliani, 1999). The Electrocardiogram signal was recorded at $256 \mathrm{~Hz}$ using a b-Alert x10 device (www.advancedbrainmonitoring.com). It was pre-processed and analysed using HRVAS (v.2014-03-21) via Matlab. Pre-processing consisted of (1) detection of R-points by means of the Pan-Tompkins algorithm (Pan \& Tompkins, 1985) and (2) visual diagnosis of ectopic beats and their corrections and the elimination of excessively noisy intervals. The analysis processed the interbeat intervals in the time-frequency domain using the Welch method and setting the frequencies of 0.05 to $0.15 \mathrm{~Hz}$ for LF and 0.15 to $0.4 \mathrm{~Hz}$ for HF (Berntson et al., 1997).

- Electroencephalogram (EEG). In order to analyse this signal, the power spectral density classification within defined frequency bands is often used. More recently, analyses of irregularity have been proposed as appropriate. Thus, the metrics used in this study were the relative power of the highbeta band (21-30 $\mathrm{Hz}$ ) of the $\mathrm{C} 3$ electrode (Choi, Kim, \& Chun, 2015) and amplitude-aware permutation entropy (AAPEn of the P3 electrode; Azami \& Escudero, 2016). The EEG signal was recorded at $256 \mathrm{~Hz}$ using a b-Alert x10 device. The raw signal was pre-processed and analysed using EEGLAB (Delorme \& Makeig, 2004) via Matlab (v.2016a). The pre-processing consisted of the signal conditioning stages and artefact identification. Signal conditioning consisted of (1) EEG traces baseline removal by mean subtraction, (2) band pass filtering between 0.5 and $40 \mathrm{~Hz}$ (Gudmundsson, Runarsson, Sigurdsson, Eiriksdottir, \& Johnsen, 2007) and (3) checking corrupted data channels, which were 
considered thus if the signal was flat more than $10 \%$ of the total duration or if the channel kurtosis reached a threshold of 5 standard deviations from allchannels kurtosis (Delorme, Makeig, \& Sejnowski, 2001). Where there was a corrupted electrode, the data were interpolated using the neighbouring electrodes, but where more than one was corrupted, the complete record was deleted (Colomer et al., 2016). Following this, the resultant signal was divided into one-second epochs. Artefact identification involved (1) checking corrupted epochs, which were considering thus if kurtosis reached the same threshold within a single channel, (2) automated detection, rejecting epochs exceeding the threshold of $100 \mu \mathrm{V}$ or a gradient of $70.00 \mu \mathrm{V}$ between samples, and (3) independent component analysis (ICA) application (Hyvärinen \& Oja, 2000), rejecting those related to an artefact. Finally, the selected metrics were calculated from the resultant signals.

The neurophysiological data were recorded at two times (Figure 1): during the baseline of the 'pre-experience' stage (four minutes) and during the experience of each CESS of the 'CESS-experience' stage (two minutes per CESS). The baseline was incorporated because the correlation of some neurophysiological metrics (EDA-Phasic, EEG-Hightbeta and EEG-AAPEn) was calculated using the normalized values with regard to the baseline $\left(M_{n}=\left(M_{\text {CEES }}-\bar{M}_{\text {BASELINE }}\right) / S D_{\text {BASELINE }}\right)$. In doing so, two outcomes were obtained: (1) the average of each CESS and (2) the analysis as a function of time, assigning to each second its relative value with regard to the initial second of each CESS $\left(M_{\text {rnTn }}=M_{n T n} / M_{n T 0}\right)$ and, for the representation, normalizing it from 0 to 1 considering the values of all CESS. 
Data analysis. After the database of participants' psychological and neurophysiological responses had been collected and anonymized, statistical analysis consisting of four sub-phases was carried out. IBM SPSS software was used.

- Phase IIA: Analysis of levels of presence in CESS simulations. The average sense of presence was analysed for each environmental simulation. We verified that this level was sufficient.

- Phase IIB: Analysis of stress psychological metrics and their relationships. First, the average levels of stress self-assessment and the State Anxiety Inventory for each CESS simulation were obtained. Next, the Friedman test and post hoc analysis with Wilcoxon signed-rank tests were conducted to identify any statistically significant differences between each pair of simulations. The Friedman test was used because the analysis was based on repeated measures comparisons, and the variables were not normally distributed, as per the results of the Kolmogorov-Smirnov test $(\mathrm{p}<0.005)$. Finally, the Spearman correlation coefficient between psychological metrics was used to examine possible relationships between the two psychological metrics.

- Phase IIC: Analysis of neurophysiological metrics related to stress. As in Phase IIB, the average levels of neurophysiological metrics related to stress for each CESS simulation were first obtained. Next, the Friedman test and post hoc analysis with Wilcoxon signed-rank tests were conducted. The analysis of these metrics was complemented with a descriptive analysis as a function of time so that it was possible to graphically observe changes in the levels of stress due to the experience of the CESS over time.

- Phase IID: Relationship between the neurophysiological and psychological metrics. The Spearman non-parametric correlation coefficient was used to 
examine possible relationships between the psychological and neurophysiological responses.

\section{Results}

\section{Phase I}

Statistical analysis of the Phase II data produced the following results:

Analysis of the individual effects of the environmental satisfaction sources on stress reduction

Participants' assessments of the 19 environmental satisfaction sources according to their effects on stress reduction were obtained (Figure 4). Five of these sources ('nice scent', 'pictures for children', 'non-intense music', 'vegetation' and 'play facilities for children') had relatively high values with respect to the others. Conversely, two sources ('space for baby buggies' and 'furniture arranged facing one another') had relatively low values. These results show the varying effects of environmental satisfaction sources on reducing the stress of fathers and mothers of child users of waiting rooms. Although the findings from this phase cannot be used as a guide for the stimuli, they suggest the directions in which efforts should be made to incorporate environmental satisfaction sources into paediatric waiting rooms. All participants reported high stress levels $(X=$ $1.03, S=0.978$ ) while they were waiting to be seen. This result indicates that they were in a highly stressful situation when they assessed the environmental satisfaction sources. [Figure 4 near here]

\section{Results: Phase II}

Statistical analysis of the Phase II data produced the following results: 
Phase IIA: Analysis of sense of presence in CESS simulations

Average levels of sense of presence per participant (according to the SUS questionnaire) for each CESS simulation were obtained (Figure 5). They were considered to be sufficient, taking into account the results obtained by studies using similar technologies (Slater \& Steed, 2000). Thus, the simulations can be considered satisfactory. [Figure 5 near here]

Phase IIB: Analysis of psychological stress metrics and their relationships

Psychological stress was measured by means of stress self-assessment and the State Anxiety Inventory. Average levels of both metrics for each CESS simulation were obtained, and significant differences were examined.

Stress self-assessment. We observe that all CESS achieve stress reduction with respect to the stress for CESS\#1 (standard waiting room). CESS\#3 achieves a greater reduction than CESS\#2, and their combination (CESS\#4) has a synergistic effect. The Friedman test indicates significant differences for the set of analysed CESS $(p=0.000)$. Post hoc analysis with Wilcoxon signed-rank tests shows that significant differences exist between all combinations except between CESS\#1 and CESS\#2 $(p=0.096$; Figure 6a).

State Anxiety Inventory. Similar stress reduction to that quantified by the stress selfassessment is observed, even though the stress reduction for CESS\#4 is less pronounced than for the others. The Friedman test shows significant differences for the set of analysed CESS $(p=0.000)$. Wilcoxon signed-rank tests show that differences exist between all combinations (Figure 6b).

Finally, bivariate correlations were obtained between both metrics using the Spearman coefficient. This analysis shows that the two metrics are significantly related (Spearman 
correlation coefficient $=0.493$, significance level $=0.000$ ). Therefore, in this study, it can be argued that stress self-assessment, although less exhaustive, provides insight when quantifying the level of psychological stress. [Figure 6 near here]

Phase IIC: Analysis of neurophysiological metrics related to stress

Neurophysiological stress was measured by means of EDA-Phasic, HRV-LFHF, EEGHighbeta and EEG-AAPEn metrics. The levels for each CESS simulation were obtained, and significant differences were examined. In addition, analysis as a function of time was performed.

EDA-Phasic. We observe that all CESS achieve a reduction in stress with respect to stress levels for CESS\#1 (standard waiting room). Although this does not follow the same pattern as at the psychological level, because CESS\#3 has a slightly higher average value than CESS\#2, the synergistic effect of CESS\#4 also appears in this metric. The Friedman test shows significant differences for the set of analysed CESS ( $p$ $=0.001)$. Wilcoxon signed-rank tests show that differences exist between all the CESS except between CESS\#2 and CESS\#3 $(\mathrm{p}=1.000)$ and between CESS\#3 and CESS\#4 ( $\mathrm{p}$ $=0.096$; Figure 7a). Figure $7 \mathrm{~b}$ shows the changes in this metric as a function of time. Although all CESS reduce stress levels with respect to the base position, CESS\#3 and CESS\#4 do so significantly quicker. It is also notable that all the CESS representations as a function of time are interrupted at approximately second 90. [Figure 7 near here] $H R V-L F H F$. All CESS achieve a stress reduction with respect to the stress levels for CESS\#1 (standard waiting room), and CESS\#4 has a synergistic effect. However, CESS\#2 and CESS\#3 have similar values. The Friedman test indicates that there are no significant differences for the set of analysed CESS $(p=0.494)$. A more specific 
analysis by means of Wilcoxon signed-rank tests shows that there are indeed no significant differences among the CESS, except between CESS\#1 and CESS\#4 $(p=$ $0.003)$ and between CESS\#1 and CESS\#3 $(\mathrm{p}=0.035$; Figure $8 \mathrm{a})$. Figure $8 \mathrm{~b}$ shows the changes in this metric as a function of time. A notable difference is found between CESS\#1 and the other CESS: This CESS does not manage to reduce stress levels from second 30 onwards, but the other configurations continue to contribute to reducing stress levels until second 60. The CESS\#1 and CESS\#3 representations as a function of time are interrupted at approximately second 90, similar to the previous metric. [Figure 8 near here]

EEG-Highbeta. This metric shows slightly different behaviour to the others. Thus, all CESS, except CESS\#2, achieve stress reduction when compared to CESS\#1 (standard waiting room), and the contribution of CESS\#3 to reducing stress is minor. Nevertheless, the synergistic effect of CESS\#4 coincides with the previous metrics. The Friedman test indicates significant differences for the set of analysed CESS $(p=0.000)$. Wilcoxon signed-rank tests show these differences between CESS\#1 and CESS\#2 ( $p=$ 0.000) and between CESS\#2 and CESS\#4 $(p=0.000$; Figure 9a). Figure $9 b$ shows the changes in this metric as a function of time. Although CESS\#2 has average values that are higher than those of CESS\#1, CESS\#2 has a greater reduction in the final period. Perhaps a more prolonged exposure to the configurations would improve its overall values. Furthermore, the strong similarity between the patterns of CESS\#1 and CESS\#2 reveals that the environmental satisfaction sources of CESS\#3 might function in a different way. The CESS\#1 representations as a function of time are also interrupted at approximately second 90. [Figure 9 near here] 
EEG-AAPEn. All CESS achieve stress reduction with respect to the stress levels for CESS\#1 (standard waiting room), and CESS\#4 has a synergistic effect. However, the reduction in CESS\#2 is marginal, with an average value that is very similar to the value for CESS\#1. The Friedman test shows significant differences for the set of analysed CESS $(p=0.005)$. Wilcoxon signed-rank tests show that these differences exist between CESS\#1 and CESS\#3 $(p=0.007)$, CESS\#1 and CESS\#4 $(p=0.000)$, CESS\#2 and CESS\#3 $(p=0.010)$ and CESS\#2 and CESS\#4 $(p=0.001$; Figure 10a). Figure 10b shows the changes in this metric as a function of time. CESS\#3 and CESS\#4, although different in their average values, follow a constant tendency in the reduction of stress levels (in contrast to CESS\#1 and CESS\#2, which experience greater disruptions). All CESS except CESS\#2 are interrupted at approximately second 90. [Figure 10 near here]

\section{Phase IID: Relationship between neurophysiological and psychological metrics}

Bivariate correlations between the neurophysiological and psychological metrics were obtained. The Spearman non-parametric correlation coefficient was used with a significance level of $\mathrm{p}<0.05$. Analysis shows stronger correlations between the stress self-assessment and the neurophysiological metrics. Thus, EDA-Phasic, EEG-Highbeta, and EEG-AAPEn metrics have a significant positive correlation with the psychological metric, which, in the case of the last EEG metric, is also applicable to the State Anxiety Inventory. There is no correlation between HRV-LFHF and the psychological metrics. Table 3 shows the results. [Table 3 near here]

\section{Discussion}

The contributions of this study relate to three areas: methodology, application and metrics to quantify stress. 
At the methodological level, there are two main contributions. First, combinations of environmental satisfaction sources were studied. Although many studies tackle the improvement in the condition of patients based on specific variables, this study provides insight into their combined effect. Second, neurophysiological measures were used to quantify stress. This allowed us to explore factors related to unconscious processes.

At the application level, our findings have two important implications: (1) stress reduction in children's companions and (2) the effect of environmental satisfaction sources based on sensory modality.

With regard to stress reduction, we suggest that it is possible to use environmental satisfaction sources to reduce the stress levels of children's companions. This result is in line with those reported by Ulrich (1991) and Kjellgren and Buhrkall (2010). We show that, with respect to the stress of the standard waiting room, stress reduction due to all combinations of environmental satisfaction sources is evident at the psychological and neurophysiological levels. The EEG-Highbeta metric offers the only contradictory result, which even differs from the other EEG metric (AAPEn). The effect of environmental satisfaction sources on stress reduction is different depending on their sensory modality. The greatest effect is achieved through the combination of visual, auditory and olfactory sources (CESS\#4), with high synergy at the psychological and neurophysiological levels. The importance of this result is that no similar experiment has been carried out previously. At the level of specific stimuli, the selected ambient environment features (CESS\#3) produce a greater effect than the interior design features (CESS\#2), especially on a psychological level. This result is interesting because hospitals generally focus on visual environmental satisfaction sources (Nanda et al., 2012), ignoring other stimuli that can significantly reduce stress. 
At the level of use of the psychological and neurophysiological metrics, three aspects should be discussed: (1) the choice of psychological metrics, (2) the choice of neurophysiological metrics and (3) the interruption of the representations of the metrics as a function of time.

As to the choice of psychological metrics, stress self-assessment may have advantages. It strongly correlates with the State Anxiety Inventory, and, contrary to this metric, correlates with most neurophysiological metrics. Despite being less exhaustive than the inventories developed for stress assessment (Tennant \& Andrews, 1976), the stress self-assessment is faster to administer. This is advantageous if the experimental phase is prolonged or HMD devices are used, because its resolution makes it difficult to read. Consequently, stress self-assessment is a tool that should be considered in studies that follow a similar methodology.

As to the neurophysiological metrics, all seem appropriate, with the exception of HRV-LFHF. This is the only neurophysiological metric that does not correlate with either of the two psychological metrics. This result supports other studies showing that HRV-LFHF is insufficient to measure the sympathovagal balance (Billman, 2013). Conversely, EEG-AAPEn correlates more strongly with the two psychological metrics than the other neurophysiological metrics. It should be noted that EEG-AAPEn has been identified as a powerful tool for the identification of stress by means of EEG (GarcíaMartínez, Martínez-Rodrigo, Zangróniz, Pastor, \& Alcaraz, 2017). The correlations of EDA-Phasic and EEG-Highbeta with stress are in line with the classic literature. Moreover, neurophysiological metrics enable analysis as a function of time. It has been found that auditory and olfactory environmental satisfaction sources reduce stress levels quicker than visual sources; this finding is consistent with studies that discuss their potential (Diego et al., 1998). In general, neurophysiological metrics confirm their 
validity for quantifying stress in virtual simulations. However, this study only considers a selection of neurophysiological metrics that were deemed appropriate based on the literature review. Future research could benefit from adding others that have also been linked to stress - such as the SD/rMSSD ratio in HRV (Sollers, Buchanan, Mowrer, Hill, \& Thayer, 2007) and the nSRR in EDA (Blechert, Lajtman, Michael, Margraf, Wilhelm, 2006) - as well as neurophysiological records of a different nature - such as pupillometry (Pedrotti et al., 2014). Adding these metrics could provide a more exhaustive study.

In terms of the disruption of the tendency in the neurophysiological metrics, it is hypothesized that this is due to the fatigue effect generated by the technology employed. This occurs with all neurophysiological metrics around second 60 for HRV-LFHF and second 90 for the others. Virtual reality may provoke different symptoms and effects, among which is an increase in arousal (Cobb, Nichols, Ramsey, \& Wilson, 1999). This effect may increase depending on the device employed, such as HMDs. Moreover, studies using similar set-ups have found comparable effects, although these effects were not specified in terms of time (Felnhofer et al., 2015). Thus, because there seems to be a notable negative effect after 90 seconds, exceeding this point may not be appropriate given the objective of the study. This effect could have conditioned the stress levels, but the period of adaptation to the virtual reality set-up and the counterbalancing design of the CESS experiences would have minimized the effects of the experience of the experiment for comparison purposes. Specific studies should be carried out in the future to evaluate this effect in detail, although it is likely to disappear as environmental simulation technologies improve.

Some limitations of the study must be taken into account, particularly when extrapolating the results to other contexts. First, the results are focused on a paediatric 
service waiting room, and the participants were companions. It is possible that the results may vary as a consequence of repeating the study in a different space and with different participant profiles. In terms of space, the environmental satisfaction sources should be adapted to the different health centre services. Regarding participant profiles, divergences may exist because of different origins of stress in staff (Gray-Toft \& Anderson, 1981) and patients (Jessee, Wilson, \& Morgan, 2000). Thus, future studies could consider all profiles to establish common strategies within the same service. Second, the waiting room that was used as the standard is representative of Spanish waiting rooms, with the same colours, smells and sounds. It is possible that the results would differ if the research was repeated in another country. Thus, in order to recreate this study, different samples and locations should be used.

\section{Conclusions}

This research examines the effect that certain paediatric service waiting room configurations have on companions' stress levels. The results suggest that a combination of multisensory environmental satisfaction sources produce a synergistic effect measurable at the psychological and neurophysiological levels. By studying them in terms of sensory modality, we observe that there is greater stress reduction through auditory and olfactory means than through visual means. Our methodological contribution is twofold: (1) simultaneous measurement of the participants' psychometric and neurophysiological responses and (2) analysis of the environmental satisfaction sources both in an isolated and combined way. The conclusions of this study may be of interest for a wide audience, including virtual reality scholars and professionals involved in the design and management of health centres. For research that focuses on or uses virtual reality as a tool, this study indicates that there may be a period (of 60-90 seconds) after which, with the technology used, an increase in arousal is generated. This 
may be a limitation in certain studies. For design and management, particularly of the paediatric service, this study offers findings that may be useful. In terms of design and construction, this study offers strategies to address the design of these spaces, and, in terms of management, the study provides empirical evidence of the importance of certain actions to reduce the stress levels of the users of these services. In short, this study can be useful for professionals seeking to study or reduce the stress levels of health centre users as well as those who use similar tools for other purposes.

\section{References}

Andrade, C. C., \& Devlin, A. S. (2015). Stress reduction in the hospital room: Applying Ulrich's theory of supportive design. Journal of Environmental Psychology, 41, $125-134$.

Andrade, C. C., Devlin, A. S., Pereira, C. R., \& Lima, M. L. (2017). Do the hospital rooms make a difference for patients' stress? A multilevel analysis of the role of perceived control, positive distraction, and social support. Journal of Environmental Psychology, 53(63-72).

Arneill, A. B., \& Devlin, A. S. (2002). Perceived quality of care: The influence of the waiting room environment. Journal of Environmental Psychology, 22(4), 345-360.

Avrahami, D. (2006). Visual Art Therapy's Unique Contribution in the Treatment of Post-Traumatic Stress Disorders. Journal of Trauma \& Dissociation, 6(4), 5-38.

Azami, H., \& Escudero, J. (2016). Amplitude-aware permutation entropy: Illustration in spike detection and signal segmentation. Computer Methods and Programs in Biomedicine, 128, 40-51.

Baker, J., \& Cameron, M. (1996). The effects of the service environment on affect and consumer perception of waiting time: An integrative review and research propositions. Journal of the Academy of Marketing Science, 24, 338-349.

Benedek, M., \& Kaernbach, C. (2010). A continuous measure of phasic electrodermal activity. Journal of Neuroscience Methods, 190(1), 80-91.

Berger, L., Tavares, M., \& Berger, B. (2013). A Canadian experience of integrating 
complementary therapy in a hospital palliative care unit. Journal of Palliative Medicine, 16(10), 1294-1298.

Berntson, G. G., Bigger, J. T., Eckberg, D. L., Grossman, P., Kaufmann, P. G., \& Malik, M. (1997). Heart rate variability: origins, methods, and interpretive caveats. Psychophysiology, 34(6), 623-648.

Beukeboom, C. J., Langeveld, D., \& Tanja-Dijkstra, K. (2012). Stress-reducing effects of real and artificial nature in a hospital waiting room. The Journal of Alternative and Complementary Medicine, 18(4), 329-333.

Billman, G. E. (2013). The LF/HF ratio does not accurately measure cardiac sympathovagal balance. Frontiers in Psychology, 4, 26.

Birnbach, D. J., King, D., Vlaev, I., Rosen, L. F., \& Harvey, P. D. (2013). Impact of environmental olfactory cues on hand hygiene behaviour in a simulated hospital environment: a randomized study. Journal of Hospital Infection, 85(1), 79-81.

Blechert, J., Lajtman, M., Michael, T., Margraf, J., \& Wilhelm, F. H. (2006). Identifying anxiety states using broad sampling and advanced processing of peripheral physiological information. Biomedical Sciences Instrumentation, 42, $136-141$.

Busse, M., Stromgren, K., Thorngate, L., \& Thomas, K. A. (2013). Parents' responses to stress in the neonatal intensive care unit. Critical Care Nurse, 33(4), 52-59.

Campbell, J., \& Ehlert, U. (2012). Acute psychosocial stress: does the emotional stress response correspond with physiological responses? Psychoneuroendocrinology, 37(8), 1111-1134.

Cannard, G. (1996). The effect of aromatherapy in promoting relaxation and stress reduction in a general hospital. Complementary Therapies in Nursing and Midwifery, 2(2), 38-40.

Choi, Y., Kim, M., \& Chun, C. (2015). Measurement of occupants' stress based on electroencephalograms (EEG) in twelve combined environments. Building and Environment, 88, 65-72.

Cobb, S. V., Nichols, S., Ramsey, A., \& Wilson, J. R. (1999). Virtual Reality-Induced Symptoms and Effects (VRISE). Presence: Teleoperators and Virtual Environments, 8(2), 169-186. 
Colomer, A., Fuentes-Hurtado, F., Ornedo, V. N., Guixeres, J. G., Ausín, J. M., \& Alcañiz, M. (2016). A Comparison of Physiological Signal Analysis Techniques and Classifiers for Automatic Emotional Evaluation of Audiovisual Contents. Frontiers in Computational Neuroscience, 10, 74.

de Kort, Y. A. W., Ijsselsteijn, W. A., Kooijman, J., \& Schuurmans, Y. (2003). Virtual laboratories: comparability of real and virtual environments for environmental psychology. Presence: Teleoperators and Virtual Environments, 12(4), 360-373.

Dedovic, K., Renwick, R., Mahani, N. K., \& Engert, V. (2005). The Montreal Imaging Stress Task: using functional imaging to investigate the effects of perceiving and processing psychosocial stress in the human brain. Journal of Psychiatry \& Neuroscience, 30(5), 319-325.

Delorme, A., \& Makeig, S. (2004). EEGLAB: An open source toolbox for analysis of single-trial EEG dynamics including independent component analysis. Journal of Neuroscience Methods, 134(1), 9-21.

Delorme, A., Makeig, S., \& Sejnowski, T. J. (2001). Automatic artifact rejection for EEG data using high-order statistics and independent component analysis. In Proceedings of the 3rd International Workshop on ICA (pp. 457-462). San Diego, USA.

Devereux, J., Rydstedt, L., Kelly, V., Westo, P., \& Buckle, P. (2004). The Role of Work Stress and Psychological Factors in the Development of Musculoskeletal Disorders. Guildford, United Kingdom: University of Surrey.

Diego, M. A., Jones, N. A., Field, T., Hernandez-Reif, M., Schanberg, S., Kuhn, C., ... Galamaga, R. (1998). Aromatherapy positively affects mood, EEG patterns of alertness and math computations. International Journal of Neuroscience, 96(3-4), $217-224$.

Diette, G. B., Lechtzin, N., Haponik, E., Devrotes, A., \& Rubin, H. R. (2003). Distraction therapy with nature sights and sounds reduces pain during flexible bronchoscopy: A complementary approach to routine analgesia. Chest, 123(3), 941-948.

Felnhofer, A., Kothgassner, O. D., Schmidt, M., Heinzle, A. K., Beutl, L., Hlavacs, H., \& Kryspin-Exner, I. (2015). Is virtual reality emotionally arousing? Investigating 
five emotion inducing virtual park scenarios. International Journal of HumanComputer Studies, 82, 48-56.

Fenko, A., \& Loock, C. (2014). The Influence of Ambient Scent and Music on Patients' Anxiety in a Waiting Room of a Plastic Surgeon. HERD: Health Environments Research \& Design Journal, 7(3), 38-59.

García-Martínez, B., Martínez-Rodrigo, A., Zangróniz, R., Pastor, J. M., \& Alcaraz, R. (2017). Symbolic Analysis of Brain Dynamics Detects Negative Stress. Entropy, 19(196), 1-16.

Gates, J. (2008). An inquiry: Aesthetics of art in hospitals. Australian Family Physician, 37(9), 761-763.

Gorski, J. A., Slifer, K. J., Kelly-Suttka, J., \& Lowery, K. (2010). Behavioral interventions for pediatric patients' acute pain and anxiety: Improving health regimen compliance and outcome. Children's Health Care, 33(1), 1-20.

Gray-Toft, P., \& Anderson, J. G. (1981). Stress among hospital nursing staff: Its causes and effects. Part A: Medical Psychology \& Medical Sociology, 15(5), 639-647.

Gudmundsson, S., Runarsson, T. P., Sigurdsson, S., Eiriksdottir, G., \& Johnsen, K. (2007). Reliability of quantitative EEG features. Clinical Neurophysiology, $118(10), 2162-2171$.

Harris, P. B., McBride, G., Ross, C., \& Curtis, L. (2002). A place to heal: Environmental sources of satisfaction among hospital Patients. Journal of Applied Social Psychology, 32(6), 1276-1299.

Herz, R. S. (2009). Aromatherapy facts and fictions: a scientific analysis of olfactory effects on mood, physiology and behavior. International Journal of Neuroscience, 119(2), 263-290.

Higuera-Trujillo, J. L., López-Tarruella, J., \& Llinares Millán, C. (2017). Psychological and physiological human responses to simulated and real environments: A comparison between Photographs, $360^{\circ}$ Panoramas, and Virtual Reality. Applied Ergonomics, 65, 398-409.

Higuera-Trujillo, J. L., Montañana i Aviñó, A., \& Llinares Millán, C. (2017). User evaluation of neonatology ward design: An application of Focus Group and Semantic Differential. HERD: Health Environments Research \& Design Journal, 
$10(2), 23-48$.

Holm, L., \& Fitzmaurice, L. (2008). Emergency Department Waiting Room Stress: Can Music or Aromatherapy Improve Anxiety Scores? Pediatric Emergency Care, 24(12), 836-838.

Hyvärinen, A., \& Oja, E. (2000). Independent component analysis: Algorithms and applications. Neural Networks, 13(4), 411-430.

Jessee, P. O., Wilson, H., \& Morgan, D. (2000). Medical play for young children. Childhood Education, 76(4), 215-218.

Kawakami, K., Takai-Kawakami, K., Okazaki, Y., Kurihara, H., Shimizu, Y., \& Yanaihara, T. (1997). The effect of odors on human newborn infants under stress. Infant Behavior and Development, 20(4), 531-535.

Kianpour, M., Mansouri, A., Mehrabi, T., \& Asghari, G. (2016). Effect of lavender scent inhalation on prevention of stress, anxiety and depression in the postpartum period. Iranian Journal of Nursing and Midwifery Research, 21(2), 197-201.

Kim, S., Kim, H. J., Yeo, J. S., Hong, S. J., Lee, J. M., \& Jeon, Y. (2011). The effect of lavender oil on stress, bispectral index values, and needle insertion pain in volunteers. The Journal of Alternative and Complementary Medicine, 17(9), 823826.

Kish, L. (1995). Survey Sampling. New York, USA: John Wiley \& Sons.

Kjellgren, A., \& Buhrkall, H. (2010). A comparison of the restorative effect of a natural environment with that of a simulated natural environment. Journal of Environmental Psychology, 30(4), 464-472.

Lang, A., Zhou, S., Schwartz, N., Bolls, P. D., \& Potter, R. F. (2000). The effects of edits on arousal, attention, and memory for television messages: When an edit is an edit can an edit be too much? Journal of Broadcasting \& Electronic Media, 44(1), 94-109.

Lazarus, R. S., \& Folkman, S. (1984). Stress, appraisal, and coping. New York, USA: Springer.

Leather, P., Beale, D., Santos, A., Watts, J., \& Lee, L. (2003). Outcomes of environmental appraisal of different hospital waiting areas. Environment and 
Behavior, 35(6), 842-869.

Lee, K. C., Chao, Y. H., Yiin, J. J., Chiang, P. Y., \& Chao, Y. F. (2011). Effectiveness of different music-playing devices for reducing preoperative anxiety: a clinical control study. International Journal of Nursing Studies, 48(10), 1180-1187.

Lehrner, J., Eckersberger, C., Walla, P., Pötsch, G., \& Deecke, L. (2000). Ambient odor of orange in a dental office reduces anxiety and improves mood in female patients. Physiology \& Behavior, 71(1-2), 83-86.

Magaret, N. D., Clark, T. A., Warden, C. R., Magnusson, A. R., \& Hedges, J. R. (2002). Patient satisfaction in the emergency department - a survey of pediatric patients and their parents. Academic Emergency Medicine, 9(12), 1379-1388.

Malliani, A. (1999). The pattern of sympathovagal balance explored in the frequency domain. Physiology, 14(3), 111-117.

Maxfield, L., \& Melnyk, W. T. (2000). Single Session Treatment of Test Anxiety with Eye Movement Desensitization and Reprocessing (EMDR). International Journal of Stress Management, 7(2), 87-101.

Moola, S., Pearson, A., \& Hagger, C. (2011). Effectiveness of music interventions on dental anxiety in paediatric and adult patients: a systematic review. JBI Database of Systematic Reviews and Implementation Reports, 9(18), 588-630.

Moya-Albiol, L., \& Salvador, A. (2001). Empleo de estresores psicológicos de laboratorio en el estudio de la respuesta psicofisiológica al estrés. Anales de Psicología, 17(1), 69-81.

Nanda, U., Chanaud, C., Nelson, M., Zhu, X., Bajema, R., \& Jansen, B. H. (2012). Impact of visual art on patient behavior in the emergency department waiting room. Journal of Emergency Medicine, 43(1), 172-181.

Nanda, U., Eisen, S., Zadeh, R. S., \& Owen, D. (2011). Effect of visual art on patient anxiety and agitation in a mental health facility and implications for the business case. Journal of Psychiatric and Mental Health Nursing, 18(5), 386-393.

Nanda, U., Pati, D., \& McCurry, K. (2009). Neuroesthetics and Healthcare Design. HERD: Health Environments Research \& Design Journal, 2(2), 116-133.

Özer, N., Özlü, Z. K., Arslan, S., \& Günes, N. (2013). Effect of music on postoperative 
pain and physiologic parameters of patients after open heart surgery. Pain Management Nursing, 14(1), 20-28.

Pan, J., \& Tompkins, W. J. (1985). A real-time QRS detection algorithm. IEEE Transactions on Biomedical Engineering, 32(3), 230-236.

Pedrotti, M., Mirzaei, M. A., Tedesco, A., Chardonnet, J. R., Mérienne, F., Benedetto, S., \& Baccino, T. (2014). Automatic stress classification with pupil diameter analysis. International Journal of Human-Computer Interaction, 30(3), 220-236.

Rashidi-Fakari, F., Tabatabaeichehr, M., \& Mortazavi, H. (2015). The effect of aromatherapy by essential oil of orange on anxiety during labor: A randomized clinical trial. Iranian Journal of Nursing and Midwifery Research, 20(6), 661-664.

Reinerman-Jones, L., Sollins, B., Gallagher, S., \& Janz, B. (2013).

Neurophenomenology: an integrated approach to exploring awe and wonder. South African Journal of Philosophy, 32(4), 295-309.

Routhieaux, R., \& Tansik, D. A. (1997). The benefits of music in hospital waiting rooms. The Health Care Supervisor, 16(2), 31-40.

Saadatmand, V., Rejeh, N., Heravi-Karimooi, M., Tadrisi, S. D., Zayeri, F., Vaismoradi, M., \& Jasper, M. (2013). Effect of nature-based sounds' intervention on agitation, anxiety, and stress in patients under mechanical ventilator support: A randomised controlled trial. International Journal of Nursing Studies, 50(7), 895-904.

Schwarz, N., \& Strack, F. (1999). Reports of subjective well-being: Judgmental processes and their methodological implications. Well-Being: The Foundations of Hedonic Psychology, 7, 61-84.

Schweitzer, M., Gilpin, L., \& Frampton, S. (2004). Healing spaces: elements of environmental design that make an impact on health. Journal of Alternative \& Complementary Medicine, 10(Supplement 1), S-71-83.

Scott, L. D., Hwang, W. T., \& Rogers, A. E. (2006). The impact of multiple care giving roles on fatigue, stress, and work rerformance among hospital staff nurses. Journal of Nursing Administration, 36(2), 86-95.

Slater, M., \& Steed, A. (2000). A Virtual Presence Counter. Presence: Teleoperators and Virtual Environments, 9(5), 413-434. 
Slater, M., Usoh, M., \& Steed, A. (1994). Depth of Presence in virtual environments. Presence: Teleoperators and Virtual Environments, 3(2), 130-144.

Sollers, J. J., Buchanan, T. W., Mowrer, S. M., Hill, L. K., \& Thayer, J. F. (2007). Comparison of the ratio of the standard deviation of the RR interval and the root mean squared successive differences (SD/rMSSD) to the low frequency-to-high frequency $(\mathrm{LF} / \mathrm{HF})$ ratio in a patient population and normal healthy controls. Biomedical Sciences Instrumentation, 43, 158-163.

Spielberger, C. D., Gorsuch, R. L., \& Lushene, R. E. (1970). Manual for the state-trait anxiety inventory. Palo Alto, USA: Consulting Psychologists Press.

Steuer, J. (1992). Defining Virtual Reality: dimensions determining telepresence. Journal of Communication, 42(4), 73-93.

Sung, S. N., \& Eun, Y. (2007). The Effect of Aromatherapy on Stress of Nurses Working in Operating Room. Journal of Korean Academy of Adult Nursing, 19(1), $1-11$.

Suter, E., \& Baylin, D. (2007). Choosing art as a complement to healing. Applied Nursing Research, 20(1), 32-38.

Tennant, C., \& Andrews, G. (1976). A scale to measure the stress of life events. Australian and New Zealand Journal of Psychiatry, 10(1), 27-32.

Thoma, M. V., la Marca, R., Brönnimann, R., Finkel, L., Ehlert, U., \& Nater, U. M. (2013). The effect of music on the human stress response. PLOS ONE, 8(8), e70156.

Ulrich, R. S. (1991). Effects of interior design on wellness: theory and recent scientific research. Journal of Health Care Interior Design, 3(1), 97-109.

Ulrich, R. S., Quan, X., Zimring, C., Joseph, A., \& Choudhary, R. (2004). The role of the physical environment in the hospital of the 21st century: a once-in-a-lifetime opportunity. The center for health design for the designing the 21st century hospital project. Concord: Robert Wood Johnson Foundation.

Valenza, G., \& Scilingo, E. P. (2014). Autonomic Nervous System Dynamics for Mood and Emotional-State Recognition. Significant Advances in Data Acquisition, Signal Processing and Classification. New York, USA: Springer. 
Venables, P. H., \& Christie, M. J. (1980). Electrodermal activity. In I. Martin \& P. H. Venables (Eds.), Techniques in Psychophysiology (pp. 3-67). New York, USA: Wiley \& Sons.

Waldon, E. G., \& Thom, J. C. (2015). Recorded music in the mental health waiting room: A music medicine investigation. The Arts in Psychotherapy, 46, 17-23.

Whelan, T. A., \& Kirkby, R. J. (2000). Parent adjustment to a child's hospitalisation. Journal of Family Studies, 6(1), 46-64.

Zhang, Y., Tzortzopoulos, P., \& Kagioglou, M. (2019). Healing built-environment effects on health outcomes: environment-occupant-health framework. Building Research \& Information, 47(6), 747-766. 
BEGINNING WITH THE PARTICIPANT

Reception, basic instructions, signature of the consent, demographical questionnaire, adaptation to virtual reality set-up, and placement of neurophysiological acquisition devices.

Recorded data: psychological data related to stress (metric: Trait Anxiety Inventory)

\section{BASE LINE}

Open Eyes + Closed Eyes

Recorded data: neurophysiological data retated to stress (base-line metrics: EDA-

Phasic, EEG-Highbeta, EEG-AAPEn)

\section{STRESSOR SETTING TASK}

Arithmetical task to adjust the difficulty of the stressor

\section{INSTRUCTIONS}

"Now you are going to listen to a recording and carry out a task. Then, you will be immersed in a space. Imagine that it is a waiting room in the paediatric service. You are waiting for your turn with your child, who you are accompanying for a checkup of certain importance.Wait sitting.After that, answer some questions about how you feel. There are no correct or incorrect answers. Don't spend too much time, but give the answer that best describes yourself. This will be repeated 4 times.

\section{PREPARATION AUDIO}

Preparation relaxing audio before the stressor task (to avoid excesive fatigue with the repetition of the sequence)

During this period the room is ventilated to avoid accumulation of smells

STRESSOR

Arithmetic tasks.

\section{STRESSOR VERIFICATION}

Recorded data: psychological data related to stress (metric: stress self-assessment)

\section{EXPERIENCE OF THE CESS}

Environmental simulation of the assigned CESS

(the interviewer adjusted the virtual reality technologies)

Recorded data: neurophysiological data related to stress (metrics: EDA-Phasic, HRV-LFHF, EEG-Highbeta, EEG-AAPEn)

\section{ASSESSMENT OF THE EXPERIENCE}

Recorded data: psychological data related to stress (stress self-assessment, and State Anxiety Inventory), and psychological data related to presence (SUS questionnaire)

\section{ENDING WITH THE PARTICIPANT}

Removal of the devices, accompaniment to the exit. 


\section{CESS\#1 and CESS\#3}

\section{CESS\#2 and CESS\#4}




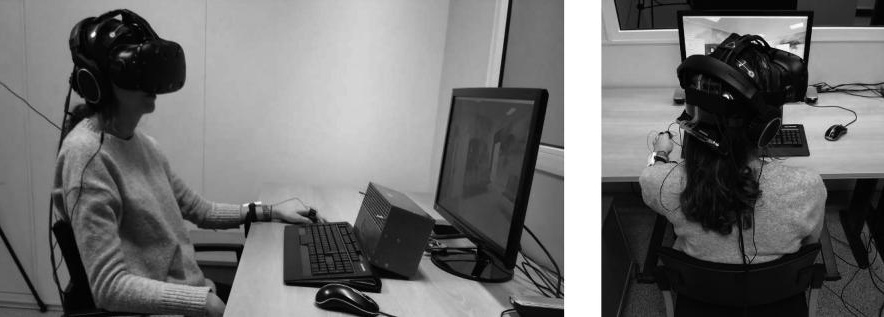




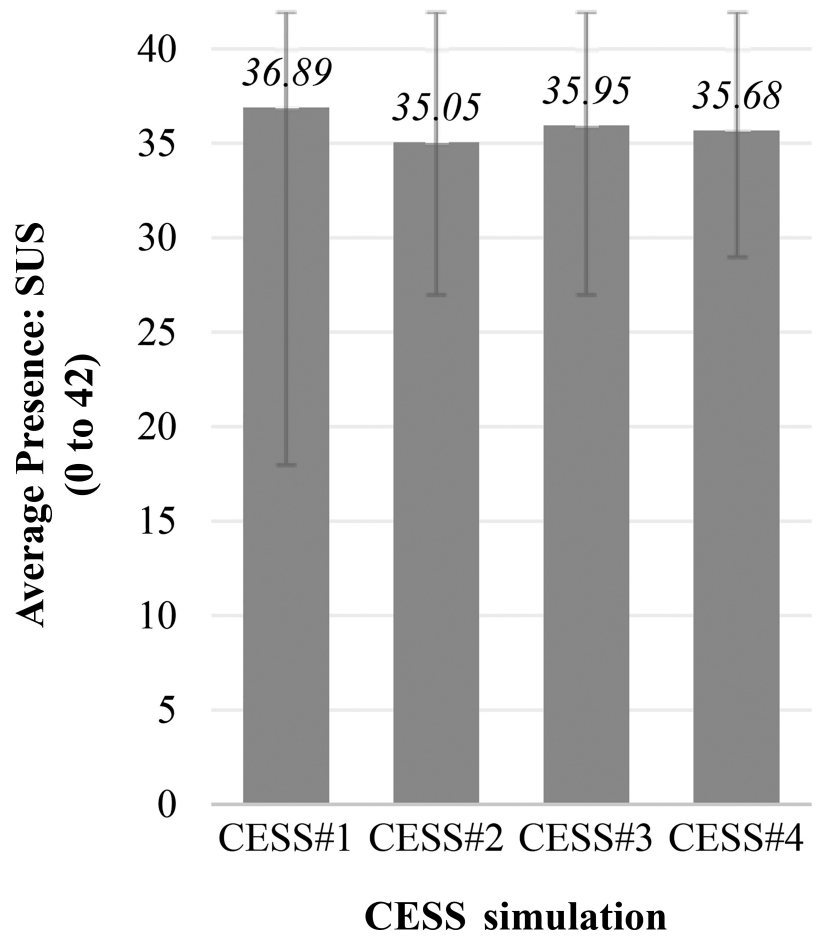




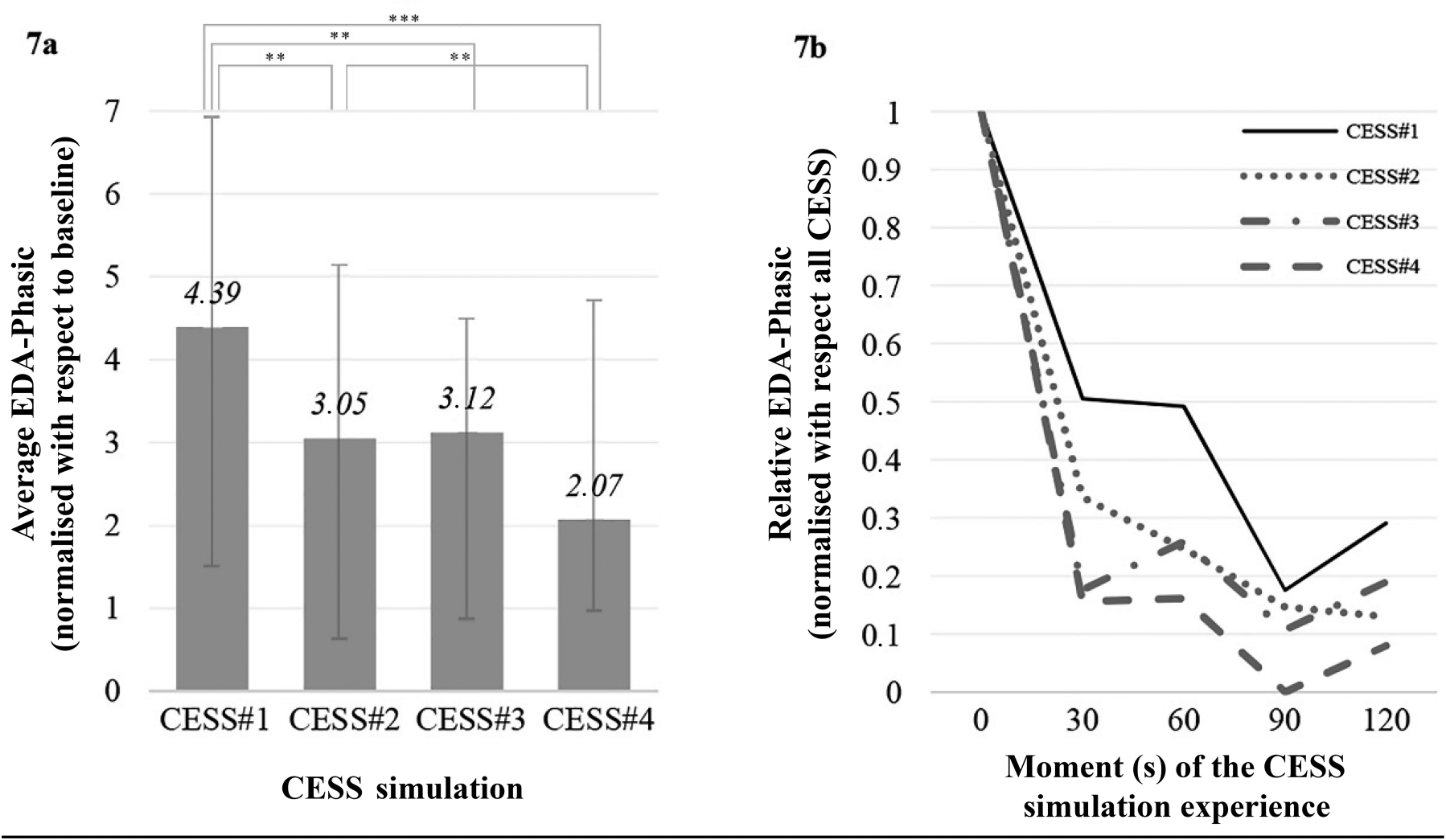

The keys indicate the comparisons and the asterisks the significance level $\left({ }^{*} p<0.05, * * p<0.01,{ }^{* * *} p<0.001\right)$ 

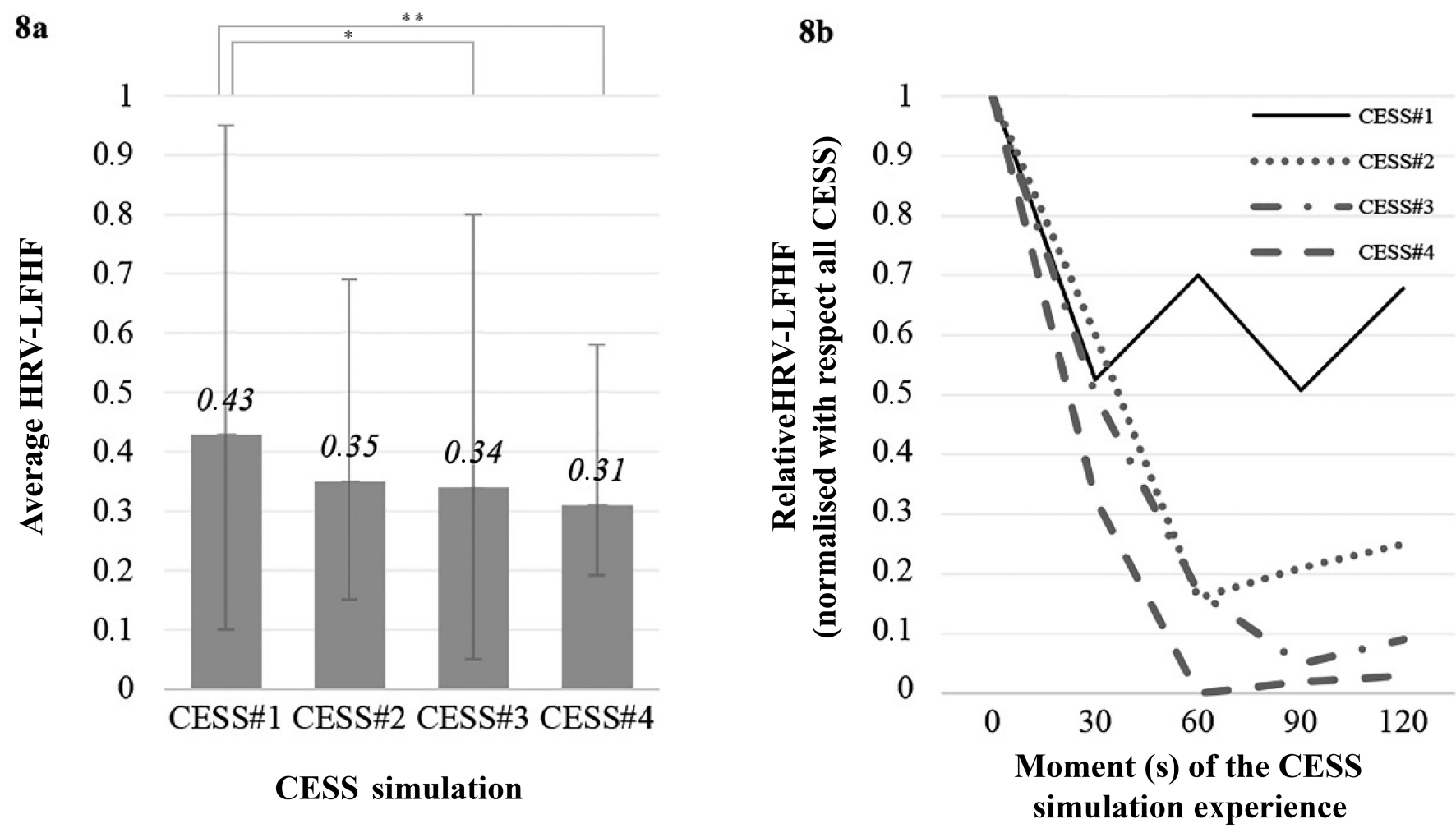

The keys indicate the comparisons and the asterisks the significance level $\left({ }^{*} p<0.05,{ }^{* *} p<0.01,{ }^{* * *} p<0.001\right)$ 

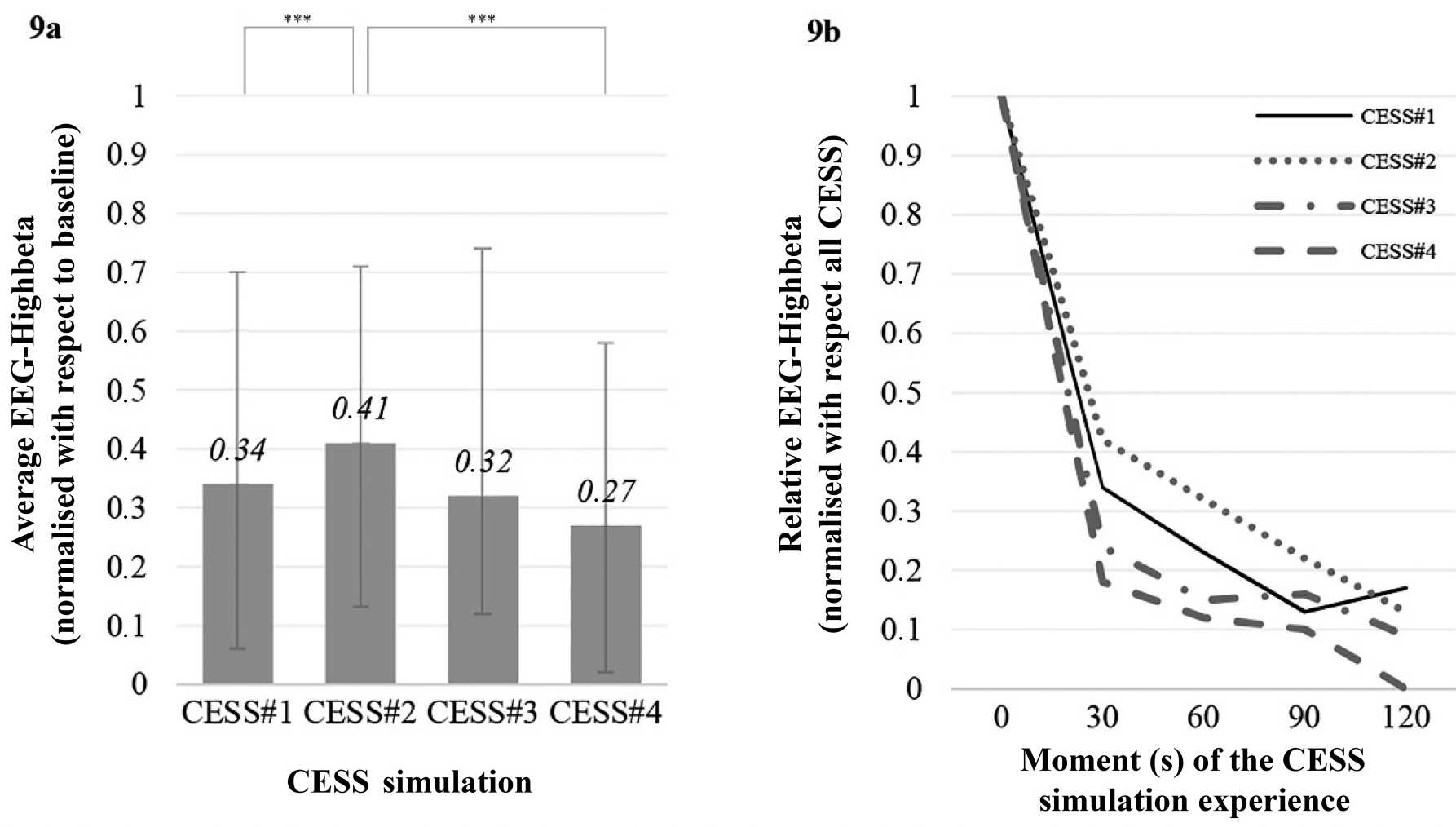

The keys indicate the comparisons and the asterisks the significance level $\left({ }^{*} p<0.05,{ }^{* *} p<0.01,{ }^{* * *} p<0.001\right)$ 
Phase I

Identify the environmental satisfaction sources of the waitingrooms which have a higher incidence on the companion's stress reduction
Field study: in situ

$$
\mathrm{N}: 120 \text { fathers/mothers }
$$

Stimuli: 20 waiting-rooms

Material: questionnaire

Dependent variables: "contribution to stress reduction" y "perceived stress"
Phase I: Analysis of the individual effects of the environmental satisfaction sources on stress reduction
Inventory of the environmental satisfaction sources which have a higher incidence on stress reduction
Field study: environmental simulation in a laboratory

Phase II

$$
\mathrm{N}: 26 \text { fathers/mothers of children }
$$

Identify how the CESS

Stimuli: four environmental simulations de waiting-rooms, each one with a different CESS based on (combinations of the results of Phase I environmental satisfaction sources) of the waiting-rooms influence the companion's stress reduction
Material: presence and stress questionnaires, and neurophysiological acquisition devices

Dependent variables: psychological ("level of presence", and "perceived stress"); and neurophysiological (registers of "EDA", "HRV", and "EEG")
Phase IIA: Analysis of levels of presence in CESS simulations

Phase IIB: Analysis of psychological stress metrics and their relationships

Phase IIC: Analysis of neurophysiological metrics related to stress

Phase IID: Relationship between Inventory of the contributions of stress reduction (at psychological and neurophysiological levels) of different CESS neurophysiological and psychological metrics

Table 1. Most relevant features of the general methodology. 
Sensory modality

\begin{tabular}{|c|c|c|c|c|c|c|}
\hline \multirow[b]{3}{*}{ CESS } & \\
\hline & \multicolumn{2}{|c|}{ Visual } & \multicolumn{2}{|c|}{ Auditory } & \multicolumn{2}{|c|}{ Olfactory } \\
\hline & $\begin{array}{c}\text { Standard } \\
\text { waiting-room } \\
\text { replica }\end{array}$ & $\begin{array}{l}\text { Vegetation, } \\
\text { and pictures } \\
\text { for children }\end{array}$ & $\begin{array}{c}\text { Standard } \\
\text { hospital } \\
\text { ambient } \\
\text { noise }\end{array}$ & $\begin{array}{c}\text { Relaxing and } \\
\text { non-intense } \\
\text { music }\end{array}$ & $\begin{array}{c}\text { Standard } \\
\text { hospital } \\
\text { simulation } \\
\text { scent } \\
\end{array}$ & $\begin{array}{l}\text { Nice relaxing } \\
\text { scent }\end{array}$ \\
\hline CESS\#1 & $\mathrm{X}$ & & $\mathrm{X}$ & & $\mathrm{X}$ & \\
\hline CESS\#2 & $\mathrm{X}$ & $X$ & $X$ & & $X$ & \\
\hline CESS\#3 & $\mathrm{X}$ & & $X$ & $\mathrm{X}$ & $\mathrm{X}$ & $\mathrm{X}$ \\
\hline CESS\#4 & $\mathrm{X}$ & $\mathrm{X}$ & $\mathrm{X}$ & $\mathrm{X}$ & $\mathrm{X}$ & $\mathrm{X}$ \\
\hline
\end{tabular}

Table 2. CESS configurations, according to the involved sensory modalities. 
Stress self-

State Anxiety

assessment

Inventory

\begin{tabular}{llll}
\hline \multirow{2}{*}{ EDA-Phasic } & Spearman correlation coefficient & $.547^{* *}$ & .034 \\
& Significance level & .000 & .790 \\
\hline \multirow{2}{*}{ HRV-LFHF } & Spearman correlation coefficient & -.056 & -.047 \\
& Significance level & .405 & .481 \\
\hline \multirow{2}{*}{ EEG-Highbeta } & Spearman correlation coefficient & $.229^{*}$ & .102 \\
& Significance level & .002 & .175 \\
\hline \multirow{2}{*}{ EEG-AAPEn } & Spearman correlation coefficient & $.479^{* *}$ & $.316^{* *}$ \\
& Significance level & .000 & .000 \\
\hline
\end{tabular}

Table 3. Correlations between the neurophysiological and psychological metrics. 